\title{
Nanostructure Fabrication Based on In-Zn Alloy Evaporation
}

\author{
Chunfei Li*, Virgil C. Solomon**, Lidong Wang***, and Limin Wang*** \\ * Department of Physics, Clarion University, Clarion, PA 16214 \\ ** Department of Mechanical \& Industrial Engineering, Youngstown State University, Youngstown, \\ $\mathrm{OH} 44555$ \\ *** Key Laboratory of Rare Earth Chemistry and Physics, Changchun Institute of Applied \\ Chemistry, Chinese Academy of Science, Changchun,130022, China
}

There are two approaches for the fabrication of nanostructures: top-down and bottom up. Related to the control of nanostructure, one advantage of top-down approach is to place different materials next to each other. This is important to realize the functions of many devices such as PN junction and transistor in semiconductor industry. It is not easy to realize same function by bottom up approach [1-3]. In the present paper, we report the synthesis and characterization of $\mathrm{ZnO}-\operatorname{In}_{2} \mathrm{O}_{3}$ junction structure based on bottom-up approach.

Our samples were synthesized based on thermal evaporation of $\operatorname{In}_{2} \mathrm{Zn}_{3}$ alloys. The alloy of approximately $0.25 \mathrm{~g}$ was placed into an alumina boat which was inserted to the center of a horizontal tube furnace. The vacuum of tube furnace was adjusted to $5.0 \times 10^{-1}$ torr and the temperature was $1150{ }^{\circ} \mathrm{C}$. Vapors were deposited on four pieces of silicon wafers of $4 \mathrm{~cm}$ long placed down stream of the tube furnace. These wafers centered on the exit of the furnace: two outside and two inside and the spacing between them is approximately $1 \mathrm{~cm}$. Obviously, the wavers placed most inside the furnace has the highest temperature and that most outside has the lowest temperature during deposition. The as deposited products were examined by scanning electron microscope (SEM), energy dispersive x-ray spectroscopy (EDS), and transmission electron microscopy (TEM).

The deposits on different wafer surfaces show different colors. We suspected the color difference corresponds to a composition change and confirmed it by EDS. It is obvious that deposit on places farther away from the furnace has more $\mathrm{Zn}$ than those close to the furnace, as shown in Fig. 1. At places in between, both $\mathrm{Zn}$ and In are found in comparable portions and junction structures are found in such places, as shown by the SEM picture in Fig. 2, where some of the junction structures are marked with arrows. EDS analysis revealed that the part with bright contrast is $\operatorname{In}_{2} \mathrm{O}_{3}$ while that with dark contrast is $\mathrm{ZnO}$. Therefore, this is an $\mathrm{In}_{2} \mathrm{O}_{3}-\mathrm{ZnO}$ junction structure. Different boiling temperature for $\mathrm{Zn}$ and In, suitable vacuum, and substrate temperature are important factors affecting the formation of such structure. This approach can be used to fabricate nanostructures with advanced physical properties, such as PN junction, which in turn can be used for the fabrication of solar cells.

\section{References}

[1] Kuo CL, Wang RC, Huang JL, Liu C, Wang CK, Chang SP, Chu WH, Wang CH, Tu CH Nanotechnology 2009; 20: 365603-365607.

[2] Jie J, Wang G, Han X, Hou JG. J. Phys. Chem 2004; B108: 17027-17031.

[3] Na CW, Bae SY, Park J. J. Phys. Chem.2005; B109: 12785-12790. 


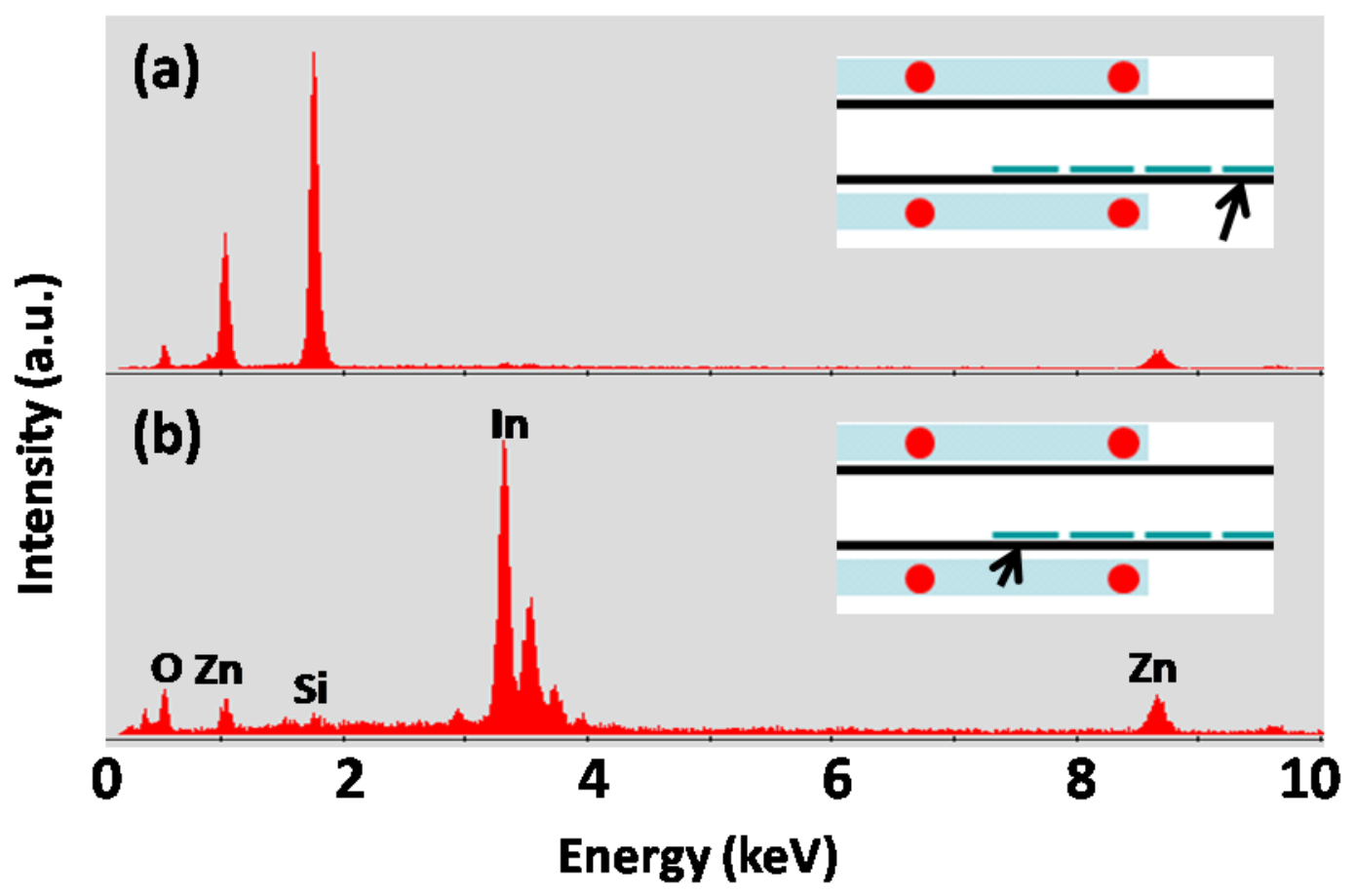

Figure 1 EDS spectra from places farther (a) and closer (b) to furnace center.

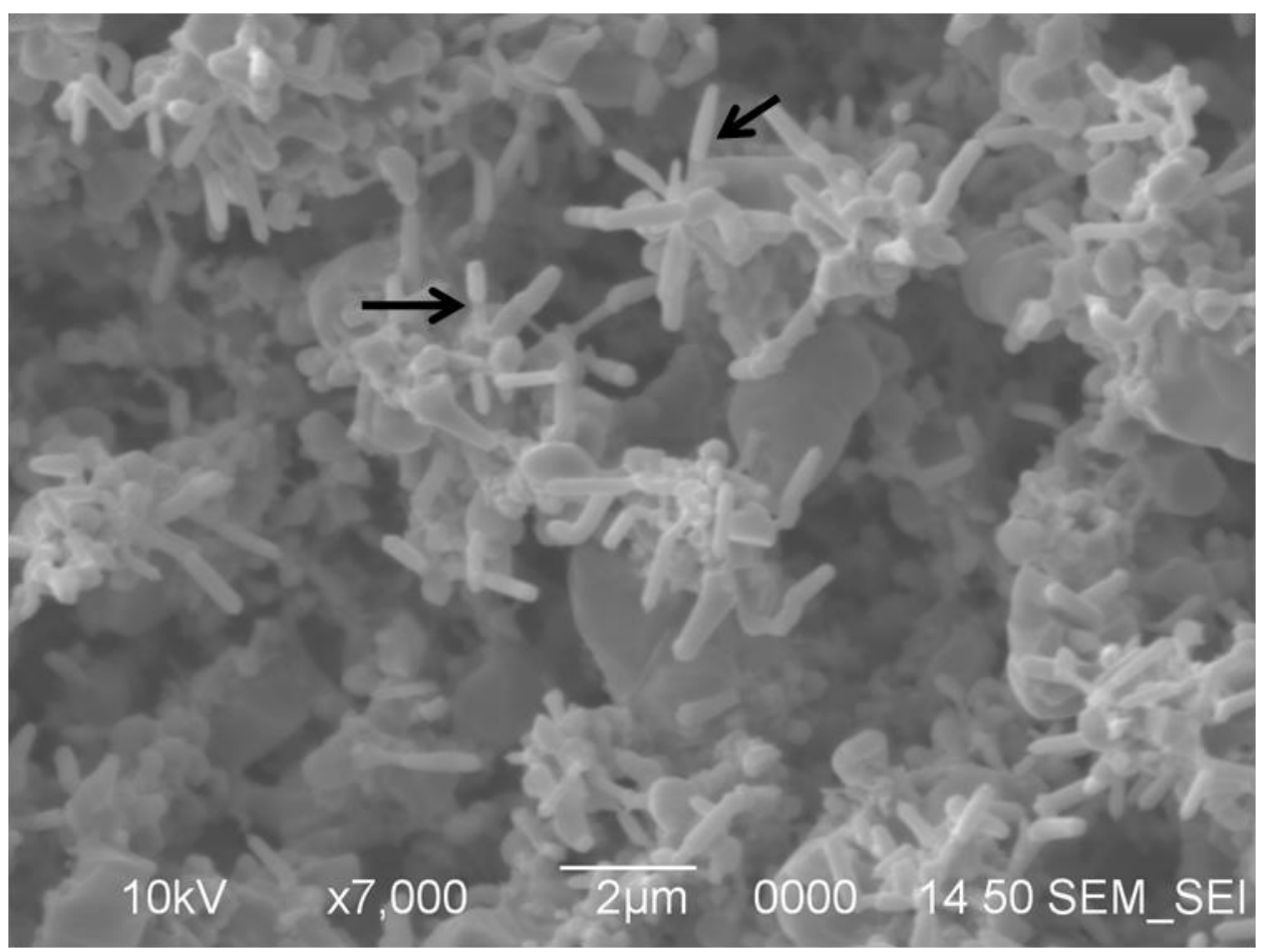

Figure 2 A representative SEM picture of junction structures. 